\title{
Livros
}

\section{Esquizofrenia: dois enfoques complementares}

Projeto Fênix - Associação Pró-Saúde Mental. 1999. São Paulo: Lemos Editorial \& Gráficos. 69 páginas. ISBN 85-7450-020-8

A esquizofrenia ainda gera muitas dúvidas, angústias e preconceitos em seus portadores, familiares, amigos e em toda a sociedade. Mesmo profissionais da área de saúde mental sentem-se freqüentemente impactar frente a um diagnóstico de esquizofrenia, devido a sua evolução, tantas vezes de difícil manejo, e às implicações decorrentes de sua freqüente cronicidade. Esse livro inaugura a Série Psicopedagógica do Projeto Fênix, que pretende publicar literatura sobre doenças mentais em uma linguagem acessível ao público leigo, utilizando informações científicas atualizadas.

Para aqueles que ainda não conhecem, o Projeto Fênix é uma entidade civil sem fins lucrativos, dirigida por portadores de doenças mentais e seus familiares. Tem como objetivo defender os direitos dos portadores de doenças mentais e buscar facilitar a recuperação e ressocialização dos mesmos por meio do fomento de grupos de auto-ajuda. Além disso, procura promover a atualização da comunidade pela divulgação de informações científicas sobre as doenças mentais.

Os "dois enfoques complementares", citados no título do livro, são de psiquiatras com larga experiência no campo da esquizofrenia e do diretor presidente do Projeto Fênix. Reúne, portanto, dois pontos de vista de fato complementares: o daqueles que se dedicam a estudar e tratar a esquizofrenia, e o daqueles que convivem com ela. Inicialmente os dois médicos abordam informações gerais bastante completas sobre o que é doença, seus sintomas, diagnóstico, causas e evolução, passando ainda por diagnósticos diferenciais, complicações e sinais de recaída. Combinando dados científicos com exemplos, fornecem informações fundamentais para a melhor compreensão do quadro. Os principais sintomas, por exemplo, são descritos um a um em linguagem clara: "O autismo é a volta para si mesmo, passando a pessoa a viver dentro de um mundo próprio fantasioso, 'desligada' do mundo exterior que a rodeia."

Um segundo item compreende vários pontos relativos ao tratamento da esquizofrenia. Começa com o tratamento medicamentoso, abordando os antipsicóticos, as indicações para as fases aguda e de remissão, os efeitos colaterais dos medicamentos e o uso dos antidepressivos e da eletroconvulsoterapia. Também aqui, a clareza da apresentação não prejudica o acesso às informações científicas. Numa segunda parte do item referente ao tratamento, são descritas as principais abordagens psicossociais. Cada uma é descrita rapidamente, destacandose os objetivos pretendidos com a sua indicação. Os trabalhos voltados ao paciente e aos familiares - psicoterapia, terapia ocupacional, acompanhamento terapêutico e orientação familiar - são abordados do ponto de vista da integração do portador aos grupos sociais com os quais se relaciona. Essa mesma visão está presente nos itens referentes à abordagem psicossocial em instituições (internação, hospital-dia, centros de convivência) e grupos de auto-ajuda, além de pensões e oficinas de trabalho protegidas - dois recursos de extrema importância, porém ainda muito pouco disponíveis em

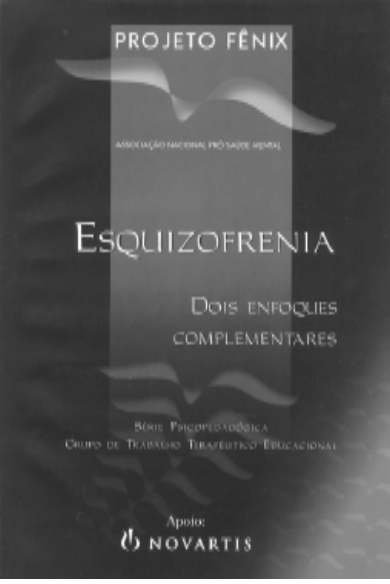
nossa realidade.

As conclusões desse primeiro enfoque são apresentadas na interessante forma de perguntas e respostas, contemplando boa parte das mais freqüentes dúvidas que familiares e público leigo em geral têm em relação à esquizofrenia.

O segundo enfoque apresentado é o dos grupos de autoajuda. Escrito em primeira pessoa, aborda com clareza e maturidade o ponto de vista dos portadores de distúrbios psiquiátricos. Mostra como conviver não somente com uma doença crônica, mas também com o tratamento, com os profissionais e com o sistema de saúde, buscando atingir juntos (portadores e profissionais da área) a mesma meta: o controle da doença e a ampliação da qualidade de vida dos doentes. A diferença entre os conceitos de tratamento, recuperação e ressocialização é enfocada em um dos itens dessa parte do livro, demonstrando como essas fases devem ser entrelaçadas para que tal meta seja atingida.

Também a importância da superação da negação da doença, vencendo os preconceitos, é apresentada como fundamental para o bom desenvolvimento do tratamento, sendo esse um dos pontos essenciais dos "passos para a recuperação" propostos pelos grupos de Psicóticos Anônimos. Somente a aceitação pode conduzir à mudança. Mas para que isso aconteça, é preciso, antes de qualquer coisa, que o diagnóstico seja corretamente definido e claramente apresentado para o paciente. Aqui a experiência pessoal do autor é de grande valia para todos que desejam compreender melhor a doença. O direito essencial de acesso às informações referentes ao diagnóstico e ao tratamento é destacado, assim como a importância da individualização quanto às características peculiares de cada um e de sua relação com os grupos aos quais pertence. Em "Postura perante os tratamentos", Luiz Barros aborda não somente o direito às informações e ao consentimento quanto às 
condutas, mas também a importante questão do vínculo terapêutico e do apoio aos familiares. Em seguida, apresenta os "Passos para a recuperação dos grupos de psicóticos anônimos", que à semelhança de outros grupos de auto-ajuda, devem ser diariamente assumidos para que a verdadeira recuperação se desenvolva.

A situação atual dos direitos dos portadores de doenças mentais, em relação à nossa Constituição e aos projetos que tramitam no Congresso, é apresentada ressaltando-se sua importância e a atuação do Projeto Fênix.

Finalmente, algumas perguntas freqüentemente realizadas por familiares e pacientes são respondidas, agora na perspectiva daqueles que convivem com a doença e com o tratamento, e valiosos "toques" para a identificação do mau atendimento são apresentados. É muito bem-vinda e oportuna a Série Psicopedagógica do Projeto Fênix, que deverá ser um instrumento de grande utilidade para o público leigo e para os profissionais de saúde mental.

Ana Cristina Belizia Schlithler Centro de Atenção Integrada à Saúde Mental da Santa Casa de São Paulo

\section{Psicopatologia e semiologia dos transtornos mentais}

Por Paulo Dalgalarrondo. 2000. Porto Alegre: Artmed. 271 páginas. ISBN 85-7307-595-3

Heidegger, num certo momento de sua obra, perguntou-se: por quê poetas em tempos de penúria? Retomo-o, transformando alguns termos e me indago: por que psicopatologistas em tempos pós-modernos? Tempos que Marshall Berman identifica como aqueles em que "tudo o que é sólido desmancha no ar".

Dalgalarrondo nos traz, no bojo de seu novo livro, pistas resolutivas para as duas interrogações. Traz a si próprio, como o psicopatologista - refiro-me ao artífice de conceitos fundadores e estáveis, transcultural e transhistoricamente, do que seja patológico no comportamento humano -, e traz poetas para ilustrar, nas imagens que só a intuição artística sabe tão bem engendrar, o que as palavras não exaurem: a essência do que é dito, os matizes mais sutis das vivências comunicadas.

Mas, como transcorre seu projeto? Alertando-nos inicialmente de que "a semiologia é a base, o pilar fundamental da atividade médica" e, após discorrer sobre as distinções entre ícones, índices e símbolos, começa por empreender seu intento: tomar e dissecar cada uma das funções psíquicas, ao longo de todo o espectro cognitivo-afetivoconativo, conceituando-lhes suas alterações psicopatológi- cas e agregando a essas, nas mais diversas correntes teóricas, um esboço de sua etiopatogenia.

Acompanha cada uma das funções psíquicas uma semiotécnica básica que nos orienta, por meio de perguntas ao paciente, no rastreamento e na identificação dos sintomas que eles possam apresentar. Finaliza o trabalho apontando as grandes síndromes psiquiátricas, também seguidas de semiotécnicas específicas que facilitem suas identificações. E, à guisa de chave-de-ouro, brinda-nos com a parte mais lúdica e singela do livro: um glossário de denominações populares relacionadas à psicopatologia, que inclui achados desde o caipiríssimo "caguira" até o nordestino "aperreado", passando por vários outros termos usados em no Brasil.

Trata-se de um trabalho de psicopatologia descritiva, que, segundo Andrew Sims, descreve e categoriza as experiências anormais como contadas pelo paciente e observadas em seu comportamento, sem uma preocupação maior de articulá-las entre si. Sob essa óptica, vem juntar-se o autor, no cenário brasileiro, embora de uma forma mais aprofundada, a Isaías Paim, autor do já clássico "Curso de psicopatologia” (primeira edição em 1969). Difere, no entanto, de Nobre de Mello, autor do também clássico "Psiquiatria/psicologia geral e psicopatologia" (primeira edição em 1970), na medida em que esse, além do puramente descritivo, empreende incursões pelo terreno fenomenológico-existencial.

Com escrita fluida e elegante, Dalgalarrondo cumpre seus propósitos. Os reparos que lhe faço são muito mais referentes à minha forma de ver a psicopatologia do que propriamente ao escopo e competência de sua empreita. Penso, por exemplo, que a etiopatogenia dos sintomas deva estar mais lotada na psiquiatria clínica, disciplina aplicada que se alimenta de ciências como a própria psicopatologia, a neurofisiologia, a neurofarmacologia e outras, e não na psicopatologia, que, a meu ver, deve contribuir apenas para a identificação e designação, o mais fiel e nuclear possível, do fato psíquico.

Além disso, alio-me à conceituação de psicopatologia por Lantéri-Laura: algo que tramita entre a psicologia do patológico e a patologia do psicológico. Ou seja, penso ser necessário, a partir do fenômeno dado, buscar, com controles próprios do método fenomenológico e pela redução eidética, articulá-lo com os outros fenômenos patológicos ou não do psiquismo do paciente, num esforço de compreensibilidade psicológica (psicologia do patológico), até que se estabeleça, na consciência do observador, a vivência do irredutível, ou seja, da essência (eidos) dos fenômenos vivenciados, ou ainda, do terreno básico de onde esses últimos emergiram. Dalgalarrondo, em alguns momentos de seu trabalho, tangencia esse procedimento, quando, entre outras passagens, fala dos "transfundos das vivências psicopatológicas e sintomas emergentes" (capítulo 24), mas não o aplica na maior parte do corpo da obra.

Autores como Jaspers ("Psicopatologia geral", 1913) e E. Minkowski ("Tratado de psicopatologia",1966) devem nos inspirar ainda a que estabeleçamos uma ponte possível entre a psicopatologia descritiva e a fenomenológica. Diferentemente de outras especialidades médicas, em que os sinais e sintomas são ícones ou índices, a psiquiatria trabalha também com símbolos. Posto isso, o pensamento, a sensibilidade e a intuição 
ainda são, e sempre serão, o instrumento propedêutico principal do psiquiatra, pois que, sem a homogeneidade conceitual do que seja cada fato psíquico não há, e não haverá, homogeneidade na abordagem clínico-terapêutica do mesmo. Essa é a nossa tarefa: mergulhar nos fenômenos que transitam entre duas consciências, a nossa, a do psiquiatra/pessoa e a do outro, a do paciente/pessoa. Deixar que os fenômenos se fragmentem, que suas partes confluam ou se esparjam, num movimento próprio e intrínseco a eles. Cabe-nos a leitura da configuração final desse jogo estrutural, sem maiores pressupostos ou intencionalidade, e com procedimentos posteriores de veri- ficação. Essa é a tarefa da Fenomenologia.

De qualquer forma, como saldo final do livro em análise, penso que o seu autor vem contribuir enormemente, mais uma vez, para com a psiquiatria brasileira e me traz à recordação o filósofo Merleau-Ponty: "A ciência manipula as coisas, mas renuncia a habitá-las". Dalgalarrondo se permite habitá-las.

Mauro Aranha de Lima

Departamento de Psiquiatria e Psicologia Médica da Faculdade de Ciências Médicas da Santa Casa de São Paulo.

\section{Errata}

Na página 234 do número 4, Vol. 21, na Comunicação Breve "Fatores de impacto de publicações psiquiátricas e produtividade científica", de Helio Elkis, a Tabela 3 saiu desalinhada. O certo é:

Tabela 3 - Comparação de médias, desvios-padrão e medianas da distribuição dos Fatores de Impacto de periódicos psiquiátricos de 1995 e 1997

\begin{tabular}{lccc}
\hline & Média & Desvio Padrão & Mediana \\
\hline FI 1995 & 1,682 & 1,753 & 1,269 \\
FI 1997 & 1,811 & 1,748 & 1,400 \\
\hline
\end{tabular}

No primeiro parágrafo da página 235 do mesmo artigo, a afirmação de que o Hospital and Community Psychiatry "perdera seu impacto" não é totalmente correta, pois o que na realidade ocorreu é que esse periódico passou a se chamar "Psychiatric Services" (vide Tabela 2). 